\title{
Adherence to the guideline 'Triage in emergency departments': a survey of Dutch emergency departments
}

\author{
Maaike AP Janssen, Theo van Achterberg, Marian JM Adriaansen, Caroline S Kampshoff and \\ Joke Mintjes-de Groot
}

\begin{abstract}
Aims and objectives. The aim of this study was to evaluate the adherence to the 2004 guideline Triage in emergency departments three years after dissemination in Dutch emergency departments.

Background. In 2004, a Dutch guideline Triage in emergency departments was developed. Triage is the first step performed by nurses when a patient arrives at an emergency department. It includes the prioritisation of patients to ensure that doctors see patients with the highest medical needs first. Although the national guideline was developed and disseminated in 2004, three years on there was no insight into the level of implementation of the guideline in practice.
\end{abstract}

Design. A cross-sectional descriptive design.

Methods. In February 2007, data were collected from ward managers and triage nurses at all emergency departments in the Netherlands $(n=108)$, using a questionnaire that was based on the recommendations and performance indicators of the guideline.

Results. In total, $79 \%$ of all 108 Dutch emergency departments responded. The main findings showed that over $31 \%$ of the emergency departments did not use a triage system. Emergency departments using the Manchester Triage System had a mean adherence rate of $61 \%$ of the guideline's recommendations and emergency departments using the Emergency System Index adhered to a mean of $65 \%$.

Conclusion. The guideline Triage in emergency departments was disseminated in 2004, but results from this study indicate that an improvement in adherence to this guideline is required.

Relevance to clinical practice. Adherence to guidelines is important to standardise practice to ensure that patients receive the appropriate treatment and to improve quality of care.

Key words: clinical guidelines, compliance, emergency departments, implementation, nurses, nursing, triage

Accepted for publication: 14 December 2010

Authors: Maaike AP Janssen, MSc, RN, Researcher, Faculty of Health and Social Studies, Department of Critical Care, HAN University of Applied Sciences; Theo van Achterberg, PhD, RN, Professor, Scientific Institute for Quality of Healthcare, Radboud University Nijmegen Medical Centre; Marian JM Adriaansen, PhD, RN, Professor, Faculty of Health and Social Studies, Department of Chronic Care, HAN University of Applied Sciences, Nijmegen; Caroline S Kampshoff, MSc, Researcher, Department of Public and Occupational Health, VU Medical Centre, EMGO Institute for
Health and Care Research, Amsterdam; Joke Mintjes-de Groot, PhD, RN, Professor, Faculty of Health and Social Studies, Department of Critical Care, HAN University of Applied Sciences, Nijmegen and Centre for Excellence in Nursing (LEVV), Utrecht, The Netherlands Correspondence: Maaike AP Janssen, Researcher, Faculty of Health and Social Studies, Department of Critical Care, HAN University of Applied Sciences, PO Box 6960, 6503 GL Nijmegen, The Netherlands. Telephone: +31 (0)243530421.

E-mail: maaike.janssen@han.nl 


\section{Background}

Triage is the first activity performed by nurses when a patient arrives at an emergency department (ED). Triage is a process of decision-making to prioritise treatment and needs of patients in ED based on clinical urgency. Triage acuity is defined as classification of patient acuity that characterises the degree to which the patient's condition is life-threatening and whether immediate treatment is needed to alleviate symptoms (Gilboy et al. 2005). Triage nurses classify patients on the basis of their need for medical attention: patients with the highest medical needs will be treated first (Manos et al. 2002, Eitel et al. 2003, Worster et al. 2004).

The number of patients arriving at EDs has increased over the past few years, partly because of self-referrals, resulting in overcrowded EDs. Therefore, there is a need for a system that prioritises patients in the order of urgency (Van Gerven et al. 2001, Roukema et al. 2006, Van der Wulp et al. 2008). Worldwide, different triage systems are used. Systems most commonly used are the Australasian Triage Scale (ATS, Australia, New Zealand, Hong Kong and Belgium), the Canadian Emergency Department Triage and Acuity Scale (CTAS, Canada), the Emergency Severity Index, also known as the Boston System (ESI, United States) and the Manchester Triage System (MTS, United Kingdom) (Cronin 2003, Murray et al. 2004, McCallum Pardey 2006, Gerdtz \& Bucknall 2007, Van Veen \& Moll 2009). All these different triage systems include assessment of the patient's most important complaint, combined with a physical examination, leading to an urgency rating. This rating indicates the length of time a patient can wait safely before being seen by a doctor (Gerdtz \& Bucknall 2000).

Although the need for a system for urgency classification of critical care patients was known, Dutch EDs did not use standardised triage systems prior to 2004. There was no protocol or guideline for urgency rating. Patients were seen by medical staff in the order of arrival instead of urgency of care, which could lead to serious consequences. This undesirable situation required changing.

Therefore, the Dutch Institute for Healthcare Improvement (CBO) and the Dutch Society of Emergency and Accident Nurses (NVSHV) developed a guideline for systematic triage in EDs in 2004 (NVSHV 2004, ElshoveBolk et al. 2007). The 2004 guideline Triage in emergency departments provides direction regarding implementation, training, resources, performance and evaluation, for nurses working in EDs in determining the urgency of patients. The guideline further offers ward managers at the EDs guidance in policy making (Bergeron et al. 2004, Göransson et al. 2005).
The introduction of the guideline in 2004 was no guarantee that the guideline would be used in practice. Research on the implementation of guidelines indicates that the use of guidelines is not always reflected in the care patients receive in practice (Meijers et al. 2006, Francke et al. 2008, Kitson et al. 2008, Forsner et al. 2010). This is also referred to as the gap between theory and practice. As a consequence, patients often do not receive the care they need (Estabrooks 1998).

This study provides insight into the current practice of triage in Dutch EDs and the level of adherence to the guideline. For this study, we formulated the following research question: what is the degree of implementation of the 2004 guideline Triage in emergency departments in Dutch EDs three years after its dissemination? Furthermore, the findings of this study and new available research findings on triage will be used to update the guideline and guide implementation activities.

\section{Methods}

\section{Study design and setting}

A cross-sectional descriptive design was used. A questionnaire was developed based on recommendations and performance indicators of the 2004 guideline Triage in emergency departments. Questions were formulated on all recommendations and performance indicators of the guideline. To ensure content validity, the questionnaire was evaluated by two members of the NVSHV, two Health Care workers at the EDs (ward manager and registered nurse), two persons of the Netherlands Centre for Excellence in Nursing (LEVV) and one person of the Scientific Institute for Quality of Healthcare. They critically reviewed the questionnaire on content and clarity of answering scales and on completeness of all aspects of triage.

For this study, a full population sample was used, including ward managers of all EDs in the Netherlands $(n=108)$. The ward managers were asked to distribute the questionnaires to one registered ED nurse trained in triage (triage nurse). Ethical approval was not needed as the questionnaire did not ask participants for medical or highly personal information and did not require a large amount of time to complete (http://www.ccmo-online.nl/main.asp?pid=1\&taal=1).

\section{Measures}

The questionnaire was divided into two components: the first component had to be filled in by a ward manager and the second by a triage nurse working in the ED. The first part of the components was identical and was related to the type of organisation, dissemination (acquaintance with the guideline) 
and use of triage systems. Only EDs using a triage system were asked to answer the follow-up questions related to adherence to recommendations from the guideline (process of triage, competences of nurses and implementation of triage). Ward managers received extra questions related to the approach of implementation and performance indicators of the guideline (process, structure and outcome measurements). For the performance indicators, evidence from clinical information was requested (Appendix).

Answering scales were a two-point scale ('yes-no') or a six-point scale ('always-mostly-often-regularly-sometimesnever'). In the introduction mail, a clarification was given for the six-point scale: 'always' meant if all nurses/doctors performed the activities all the time $(100 \%)$, 'mostly' meant within 80-99\%, 'often' within 60-79\%, 'regularly' within 40-59\%, 'sometimes' within $1-39 \%$ and 'never' $0 \%$. The questions included room for clarification.

\section{Data collection}

A list of hospitals in the Netherlands with the names of all EDs was collected from the NVSHV. All hospitals were contacted and asked whether the hospital had an ED and what the name of the ward manager was to whom we could send the questionnaire. Based on website information, university and teaching hospitals (http://www.rivm.nl, http://www.stz-ziekenhuizen.nl) were identified. The remaining hospitals of the list were classified as non-teaching hospitals. In February 2007, the questionnaires were sent to ward managers of all EDs (eight university hospitals, 28 teaching hospitals and 72 non-teaching hospitals) with the kind request to fill in the first part of the questionnaire and to distribute the other part to a nurse working at the department. Ward managers of triage-performing EDs, were asked to forward the questionnaire to a triage nurse, as nurses who filled in the questionnaire had to have knowledge on triage.

To improve response, stamped return envelopes were added. As the questionnaires were anonymous, a reminder to return the questionnaire was sent to all ward managers after three weeks. After five weeks, another reminder was sent including the questionnaires. In addition, information on the research was published on the websites of the Department of Critical Care (http://www.laiz.nl), the NVSHV (http:// www.nvshv.nl) and the Dutch Community Trauma Nursing (STNN, http://www.trauma-nursing.nl/stnn/).

\section{Analytical methods}

Data were analysed using Statistical Package for Social Sciences (SPSS) 14.0 (IBM Nederland B.V., Nieuwegein, The
Netherlands). The statistical analyses included descriptive frequency distributions of all variables. Data from all EDs were analysed by type of organisation, dissemination of the guideline and use of a triage system. Only the data of those EDs that used a triage system were analysed in association with implementation, personnel, performance, resources, evaluation and performance indicators.

When activities were performed in $80 \%$ or more, this was seen as high and sufficient. For that reason, the six-point scale questions were transformed into a two-point scale (a 'yes' and 'no' scale): the 'yes' category including 'always' and 'mostly', the 'no' category including 'often', 'regularly', 'sometimes' and 'never'. The category 'often' was excluded from the 'yes' category and included in the 'no' category because the 'no' category indicates room for improvement.

Analyses were performed on the total sample, separately for each respondent group (ward managers and triage nurses) and type of hospital (university hospitals, teaching hospitals and non-teaching hospitals). Of each type of triage system, the percentage of follow-up was calculated with the median, spread and interquartile range of scores. Differences between ward managers and nurses were analysed on aspects related to triage. The expectation was that they scored differently on the questions, as they would have other interests related to triage. For example, ward managers have to ensure that nurses perform triage and facilitate organisational aspects like education and rooming facilities. Nurses are responsible for the professional performance of triage. As university hospitals consisted of only eight hospitals, analyses of the university hospitals were grouped with analyses of the teaching hospitals.

Pearson's chi-square tests were used to detect differences between groups (type of hospital and ward managers vs. nurses). To ensure the overall change of making a type I error for multiple comparisons, statistical significance was set at $p<0.0019$ after Bonferroni correction $(0 \cdot 05 / 26=0 \cdot 0019)$.

\section{Results}

A total of 158 of 216 questionnaires (73\%) were returned (80 ward managers and 78 triage nurses). A total of 81 of 108 EDs $(75 \%)$ returned the questionnaires. In addition, four ward managers responded by telephone, stating that they would not return the questionnaire, because their ED was already involved in other research concerning triage or was not using a triage system or implemented the guideline recently.

\section{Type of organisation}

The participating EDs were representative of the Dutch context. All eight university hospitals responded (100\%). 
For the 28 teaching hospitals, the response rate was $82 \%$ ( $n=23)$, and for the 72 non-teaching hospitals, the response rate was $69 \%(n=50)$.

\section{Dissemination}

All in all, $99 \%$ of the ward managers $(n=79)$ and $92 \%$ of the triage nurses $(n=72)$ knew about the national guideline. The main source of dissemination of the guideline was the Dutch Society of Emergency and Accident Nurses (NVSHV). Triage nurses stated that ward managers were also an important source. Table 1 shows other sources that were employed for the dissemination of the guideline.

\section{Triage systems}

Almost 39\% ( $n=33)$ of the EDs did not use a triage system. Patients were seen by a nurse in the order of arrival instead of urgency of care. Two standardised triage systems were used at EDs in the Netherlands: 42 EDs used the MTS and six EDs the Emergency System Index (ESI). Four EDs reported the use of a self-developed triage system.

\section{Adherence to recommendations and performance indicators}

Figure 1 shows the adherence to all recommendations and performance indicators of the 2004 guideline Triage in emergency departments for each of the triage systems, based on the questionnaire of the ward managers. EDs that used the MTS had a mean adherence rate of $61 \%$, EDs using the ESI had a mean adherence rate of $65 \%$, whereas EDs using a self-developed triage system had a mean adherence rate of $29 \%$.

Table 1 Sources of dissemination of the guideline 'Triage at the emergency departments'

\begin{tabular}{lcc}
\hline Sources & \multicolumn{2}{c}{ Ward managers } \\
$(n=80) n(\%)$ & $\begin{array}{c}\text { Triage nurses } \\
(n=78) n(\%)\end{array}$ \\
\hline Colleague & $5(6)$ & $13(17)$ \\
Internet & $9(11)$ & $3(4)$ \\
Professional journals & $26(33)$ & $7(9)$ \\
NVSHV & $49(61)$ & $21(27)$ \\
STNN & $16(20)$ & $11(14)$ \\
CBO $^{3}$ & $19(24)$ & $2(3)$ \\
Ward managers & $3(4)$ & $22(28)$ \\
Other & $14(18)$ & $7(9)$
\end{tabular}

NVSHV, Dutch Society of Emergency and Accident Nurses; STNN, Dutch Community Trauma Nursing; CBO, Dutch Institute for Healthcare Improvement.

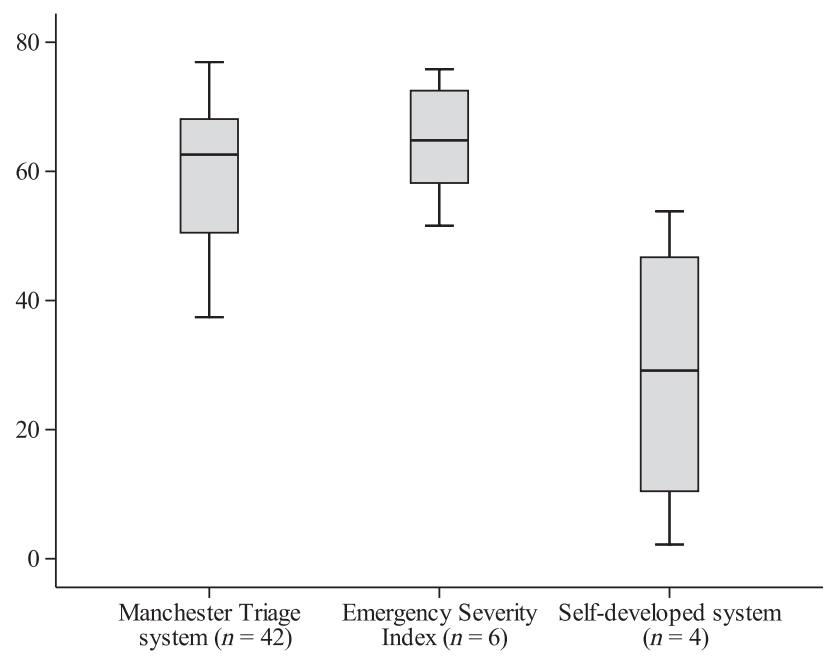

Figure 1 Adherence to recommendations vs. type of triage system (\%).

\section{Guideline implementation}

The questionnaire for the ward manager included questions related to the approach to guideline implementation. The answers to these questions are presented in Table 2. Some ward managers pointed out that the doctors were informed about the procedure of triage after triage was established. In $87 \%$ of the EDs $(n=69)$, implementation of the triage system occurred by change agents consisting of a ward manager, a project leader or an advisor. About half of the EDs used a systematic method for implementation and reserved some type of budget for the implementation of a triage system.

\section{Training}

The guideline recommends that nurses performing triage follow an education in Acute Care, the Trauma Nursing Core Course (TNCC), the Emergency Nursing Paediatric Course (ENPC) and didactic training in triage. Furthermore, they

Table 2 Approach to implementation of triage systems

\begin{tabular}{ll}
\hline Implementation & $\begin{array}{l}\text { Ward managers } \\
(n=52) * n(\%)\end{array}$ \\
\hline Top-down & $22(42)$ \\
Multidisciplinary & $40(77)$ \\
Change agents & $45(87)$ \\
Systematic method for implementation & $24(46)$ \\
Budget reserved for & \\
ICT system & $33(64)$ \\
Personnel & $25(48)$ \\
Training & $27(52)$ \\
Triage room & $28(54)$ \\
\hline
\end{tabular}

*Only ward managers of emergency departments that use a triage system filled in the questionnaire.

ICT system, Information Communication Technology system. 
have to have more than one-year clinical work experience. On average, nurses had a more positive score on trained triage nurses compared with ward managers, except for training by colleagues. There were statistically significant differences in answers found between nurses and ward managers regarding TNCC and work experience (Table 3).

\section{Resources}

Table 3 shows the triage resources that were available in the EDs. Almost $80 \%$ of all EDs have created a triage room, whereas about $70 \%$ used an Information Communication Technology system (ICT system), formulated a triage workgroup and had information brochures in the waiting room.

\section{Performance}

Triage nurses did not always carry out triage of every patient arriving at an ED. According to the ward managers, a triage nurse saw nearly two out of three patients within five minutes of arrival. Pain assessment was carried out among almost all patients. Two out of every three EDs formulated a triage protocol based on the guideline for triage and consensus at the ED. The protocols contained agreements concerning the tasks of the triage nurse, what to do when the ED is crowded and the coordination of the patient flow.

\section{Evaluation}

Table 4 additionally presents results related to the evaluation of triage at the EDs. Over $50 \%$ of EDs evaluated the trial period. The evaluations led to changes related to responsibilities of the triage nurses and the doctors, interventions triage nurses are permitted to perform, content of triage assessments, development of pain protocols, ICT systems and use of triage rooms. Multidisciplinary reflection occurred less often than monodisciplinary reflection. Based on these evaluations, improvements were made associated with adding necessary supplies to triage rooms (e.g. computers, stretchers, thermometers, dressings), increasing personnel numbers (having triage nurses on day, evening and night shifts), agreements on the tasks of triage nurses, development of pain protocols and adjustments to ICT systems.

\section{Performance indicators}

Table 5 shows results associated with the performance indicators. There is a wide range in the registration of the indicators. Registration of the reason for leaving the ED occurs most often (over 90\%). The indicator 'registration of reason for not achieving the target time' is used least of all performance indicators. Sixty-four per cent of the EDs $(n=32)$ registered incidents of aggression. Of these EDs, five provided the number of aggressive incidents at their department.

\section{Discussion}

This study was designed to examine the adherence of EDs in the Netherlands to the 2004 guideline Triage in emergency departments. Although the study is performed in a Dutch setting, the results may be relevant for other countries as well, indicating potential lack of adherence to triage guidelines in EDs.

The guideline was disseminated in 2004, and because most ward managers and nurses know about its existence, the

\begin{tabular}{lllll}
\hline & $\begin{array}{c}\text { Ward managers } \\
(n=52) n(\%)\end{array}$ & $\begin{array}{l}\text { Triage nurses } \\
(n=54) n(\%)\end{array}$ & $\begin{array}{l}\text { Difference } \\
\%(95 \% \text { CI })\end{array}$ & $p$-value \\
\hline Training for triage nurses & & & & \\
Education acute care & $45(87)$ & $53(98)$ & $-10(-19$ to 0$)$ & $0 \cdot 0423$ \\
TNCC & $31(60)$ & $47(87)$ & $-26(-43$ to -10$)$ & $0 \cdot 0019^{*}$ \\
ENPC & $5(10)$ & $18(33)$ & $-23(-39$ to -7$)$ & $0 \cdot 0045$ \\
1-2 years work experience & $33(64)$ & $52(96)$ & $-32(-46$ to -18$)$ & $0 \cdot 0000^{*}$ \\
Certified training (STNN) & $12(23)$ & $16(30)$ & $-8(-26$ to 11$)$ & $0 \cdot 4109$ \\
Training by colleagues & $28(54)$ & $25(46)$ & $7(-13$ to 28$)$ & $0 \cdot 4747$ \\
On-the-job training & $40(77)$ & $53(98)$ & $-18(-30$ to -7$)$ & $0 \cdot 0024$ \\
Multi-disciplinary training & $17(33)$ & $21(39)$ & $-5(-25$ to 15$)$ & $0 \cdot 6157$ \\
Resources & & & & - \\
Information brochure & $35(67)$ & - & & - \\
Triage room & $41(79)$ & - & & - \\
ICT system & $37(71)$ & - & & \\
Triage group & $37(71)$ & - & & - \\
\hline
\end{tabular}

*Statistically significant ( $p$-value $<0 \cdot 0019$ ) between ward managers and triage nurses. TNCC, Trauma Nursing Core Course; ENPC, Emergency Nursing Paediatric Course; STNN, Dutch Community Trauma Nursing; ICT system, Information Communication Technology system.

Table 3 Training for nurses and triage resources in the emergency department 
Table 4 Performance and evaluation of triage

\begin{tabular}{|c|c|c|c|c|}
\hline & $\begin{array}{l}\text { Ward managers } \\
(n=52) n(\%)\end{array}$ & $\begin{array}{l}\text { Triage nurses } \\
(n=54) n(\%)\end{array}$ & $\begin{array}{l}\text { Difference } \\
\%(95 \% \mathrm{CI})\end{array}$ & $p$-value \\
\hline \multicolumn{5}{|l|}{ Performance triage } \\
\hline $\begin{array}{l}\text { Triage assessment of } \\
\text { all incoming patients }\end{array}$ & $42(81)$ & $44(81)$ & $2(-13$ to 17$)$ & 0.7938 \\
\hline $\begin{array}{l}\text { Triage assessment within } \\
5 \text { minutes after arrival }\end{array}$ & $32(62)$ & $41(76)$ & $-12(-30$ to 6$)$ & $0 \cdot 1987$ \\
\hline $\begin{array}{l}\text { Urgency rating within } \\
3-5 \text { minutes }\end{array}$ & $49(94)$ & $50(93)$ & $7(-3$ to 17$)$ & $0 \cdot 1854$ \\
\hline Triage protocol & $32(62)$ & $29(54)$ & $7(-9$ to 23$)$ & $0 \cdot 2804$ \\
\hline Pain assessment & $49(94)$ & $54(100)$ & $-4(-11$ to 3$)$ & $0 \cdot 2777$ \\
\hline Treatment during assessment & $28(54)$ & $41(76)$ & $-20(-38$ to -2$)$ & $0 \cdot 0342$ \\
\hline \multicolumn{5}{|c|}{ Treatments } \\
\hline Blood sampling & $46(88)$ & $52(96)$ & $-1(-10$ to 9$)$ & $0 \cdot 8854$ \\
\hline Electrocardiograms & $28(54)$ & $25(46)$ & $12(-8$ to 31$)$ & $0 \cdot 2381$ \\
\hline Controls & $39(75)$ & $44(81)$ & $0(-16$ to 15$)$ & 0.9592 \\
\hline Painkillers & $46(88)$ & $47(87)$ & $8(-4$ to 20$)$ & $0 \cdot 1664$ \\
\hline $\begin{array}{l}\text { Work agreement to } \\
\text { carry out treatments }\end{array}$ & $40(77)$ & $41(76)$ & $11(-9$ to 30$)$ & $0 \cdot 3607$ \\
\hline $\begin{array}{l}\text { Responsibility for patients in } \\
\text { waiting room referred } \\
\text { to triage nurse }\end{array}$ & $43(83)$ & $41(76)$ & $12(-4$ to 27$)$ & $0 \cdot 1455$ \\
\hline \multicolumn{5}{|l|}{ Evaluation } \\
\hline Trial period $(n=30)$ & $30(58)$ & $29(54)$ & $3(-17$ to 23$)$ & $0 \cdot 3956$ \\
\hline $\begin{array}{l}\text { Adjustments after } \\
\text { trial period }\end{array}$ & $20(67)$ & $16(55)$ & $12(-14$ to 37$)$ & $0 \cdot 3741$ \\
\hline Multidisciplinary reflection & $26(50)$ & $21(39)$ & $14(-5$ to 34$)$ & $0 \cdot 1522$ \\
\hline Monodisciplinary reflection & $41(79)$ & $30(56)$ & $26(9-44)$ & $0 \cdot 0035$ \\
\hline $\begin{array}{l}\text { Sufficient budget for } \\
\text { implementation }\end{array}$ & $28(54)$ & - & & - \\
\hline $\begin{array}{l}\text { Patient satisfaction } \\
\text { measured }(n=35)\end{array}$ & $35(67)$ & $11(20)$ & $49(31-67)$ & $0 \cdot 0000 *$ \\
\hline Waiting time & $30(86)$ & - & & - \\
\hline Urgency classification & $19(54)$ & - & & - \\
\hline Pain & $16(46)$ & - & & - \\
\hline Attitude & $32(91)$ & - & & - \\
\hline Privacy & $26(74)$ & - & & - \\
\hline $\begin{array}{l}\text { Health workers satisfaction } \\
\text { measured }(n=33)\end{array}$ & $33(64)$ & $27(50)$ & $18(-1$ to 38$)$ & $0 \cdot 0639$ \\
\hline Decreased aggression & $24(73)$ & - & & - \\
\hline Triage system & $20(61)$ & - & & - \\
\hline ICT system & $18(55)$ & - & & - \\
\hline Triage room & $18(55)$ & - & & - \\
\hline
\end{tabular}

*Statistically significant $(p$-value $<0.0019)$ between ward managers and triage nurses. ICT system, Information Communication Technology system. expectation was that nearly all EDs would use a triage system by now. Additionally, the Netherlands Health Care Inspectorate (IGZ) and the NVSHV recommend the use of the guideline, which should have advanced its use as well (NVSHV 2004, Jochems 2006). Nevertheless, over 38\% of the EDs that filled in the questionnaire did not perform triage using a standardised triage system. Some EDs stated that they would implement a triage system within one year. Another reason why EDs have not implemented a triage system could be the fact that a new triage system is currently being developed: the Dutch Triage System (NTS). Collaboration between the Dutch College of General Practitioners (NHG), the NVSHV, the Netherlands Mental Health Care Association (GGZ Nederland) and the National Institute for Guidelines EMS (Stichting LAMP) should result in one system for telephonic and physical triage for all acute care settings (general practitioner, ambulance, ED and mental health care) (NTS 2006). An agreement has been made between the four 
Table 5 Performance of triage related to the performance indicators of the guideline

\begin{tabular}{|c|c|}
\hline Performance indicators & $\begin{array}{l}\text { Ward managers } \\
(n=50) n(\%)\end{array}$ \\
\hline Registration of urgency rating & $38(76)$ \\
\hline $\begin{array}{l}\text { Registration of time between arrival and first } \\
\text { contact triage nurse }\end{array}$ & $36(72)$ \\
\hline Registration of duration of triage process & $14(28)$ \\
\hline $\begin{array}{l}\text { Registration of time between urgency rating } \\
\text { and first contact with doctor }\end{array}$ & $35(70)$ \\
\hline $\begin{array}{l}\text { Registration of \% of target time according } \\
\text { the protocol }\end{array}$ & $21(42)$ \\
\hline $\begin{array}{l}\text { Registration of reason for not achieving } \\
\text { target time }\end{array}$ & $8(16)$ \\
\hline $\begin{array}{l}\text { Registration of first contact with doctor } \\
\text { and leaving the ED }\end{array}$ & $38(76)$ \\
\hline Registration of reason for leaving the ED & $46(92)$ \\
\hline $\begin{array}{l}\text { Registration of urgency rating related to } \\
\text { dismissal from ED }\end{array}$ & $14(28)$ \\
\hline Registration of retriage $(n=10)$ & $10(20)$ \\
\hline \multicolumn{2}{|l|}{ Reason } \\
\hline Max. waiting time & $4(40)$ \\
\hline Pain intervention & $6(60)$ \\
\hline Other & $5(50)$ \\
\hline $\begin{array}{l}\text { Registration of \% of patients without } \\
\text { urgency rating }\end{array}$ & $26(52)$ \\
\hline \multicolumn{2}{|l|}{ Registration of information regarding } \\
\hline Retriage & $9(18)$ \\
\hline Urgency rating & $11(22)$ \\
\hline Waiting time & $10(20)$ \\
\hline Pain & $10(20)$ \\
\hline Registration of aggression $(n=32)$ & $32(64)$ \\
\hline $\begin{array}{l}\text { EDs who gave actual number of aggression } \\
\text { incidents }\end{array}$ & $5(16)$ \\
\hline
\end{tabular}

ED, emergency department.

organisations that as soon as this new system is in place the acute care settings in the Netherlands must use this system. However, this process could take several more years and EDs need to perform systematic triage during this time.

The MTS is the triage system used most frequently. This could be explained by the fact that the guideline explicitly recommends this triage system on the basis of conclusions on triage in an earlier literature review (NVSHV 2004, ElshoveBolk et al. 2007). The ESI is also used in the Netherlands. The use of other international triage systems was not found. Although the MTS and ESI are valid and reliable systems (Travers et al. 2002, Speake et al. 2003, Baumann \& Strout 2007, Storm-Versloot et al. 2009), little research has been conducted on the validation of MTS and ESI for the Dutch context. One study assessed the reliability and validity of the MTS in two EDs in the Netherlands. The authors found a moderate to substantial inter-rater reliability, and nurses were consistent in their decision-making around urgency classification. The MTS appeared to be more sensitive in its use for children who need immediate or urgent care than for other patients in the ED (Van der Wulp et al. 2008). Two studies examined the validity of the MTS in paediatric emergency care. The authors found a moderate validity (Roukema et al. 2006, Van Veen et al. 2008). A fourth study looked at the validation of the ESI triage algorithm in selfreferred patients in one ED in the Netherlands. The authors declared that the ESI triage algorithm is likely to be reliable in predicting the severity of patients' condition in the Netherlands (Elshove-Bolk et al. 2007). Although these studies are available, more research into the validation and comparison of the two systems for Dutch EDs is needed. Four EDs used a self-developed triage system. It remained unclear how these self-developed systems functioned. These systems are not validated, and it appears that they have little in common with the recommendations of the guideline.

Guidelines are valuable tools to promote evidence-based practice. Although the dissemination of the guideline seems to be good, thorough implementation of the guideline seems to be lacking. Our study provides no clear insight into the factors that may have contributed to the moderate implementation of the guideline. One explanation could be that many EDs did not use a systematic approach to implementation (Grol \& Wensing 2005). Another reason could be that only half of the EDs had a budget for the implementation of the guideline at their disposal. It is important that managers take into account that successful implementation of guidelines can lead to extra costs (Ploeg et al. 2007). Over $80 \%$ of the EDs made use of a change agent. Other studies suggest that the use of change agents facilitate guideline implementation (Doumit et al. 2007, Ploeg et al. 2007). Further research related to factors that influenced implementation of the guideline is needed to develop strategies to increase the use of the guideline.

Evaluation is an important step in the process of implementing a guideline (Grol 1997, Wollersheim et al. 2005). Performance indicators can be used to evaluate the use of the guideline (Wollersheim et al. 2005, Forsner et al. 2008). The indicators give insight into the delivered quality of patient care. Furthermore, the actual care can be compared with the recommended care in the guideline (Nelen et al. 2007). Although ward managers can use the performance indicators of the guideline for policy making regarding triage, only half of the ward managers stated that they actually used the performance indicators. One reason for not using the indicators was that EDs did not have a digital registration system. Lack of resources to register indicators is one of the most important factors that hinders the use of performance indicators (Cabana et al. 1999, De Vos et al. 2010). 
An immense variance between the adherences to different recommendations of the guideline exists. The recommendation with the lowest rate of compliance is the ENPC. The highest rate of compliance was found for pain assessment. A study on clinical guidelines indicated different reasons for low compliance with recommendations. First, the recommendation could be incorrect because of a lack of scientific evidence for the recommendation. Second, the influence of the development group or the influence of different parties involved in development of the recommendation (for example patients, doctors, managers and the government) (Woolf et al. 1999).

Some EDs modified a few recommendations. One recommendation often modified was 'seeing patients within five minutes of arrival', which was often changed to 'within 10 minutes of arrival' as five minutes was found to be too short. Rogers (1995) refers to this as re-invention of the innovation. Although this study gives insight into whether the recommendations of the guideline are used by the EDs, it provides no insight into the factors that influence the use of the guideline. Therefore, we recommend a study on factors that promote or hinder the uptake of the guideline.

Triage nurses and ward managers achieved overall similar scores in regard to the recommendations. Only statistically significant differences between the scores of triage nurses and ward managers were found among recommendations related to TNCC, work experience and measurement of patient satisfaction. Triage nurses had a higher score related to training and performance, while ward managers scored higher on the recommendations of evaluation. One explanation might be that the task of the ward managers is more focused on evaluation, whereas nurses are responsible for the performance of triage. No statistically significant differences were found between types of hospital.

\section{Limitations}

This study has some limitations that weaken the credibility of the findings. The first limitation is related to the development of the questionnaire. As the questionnaire was meant to gain insight into the adherence of the guideline, the questionnaire was based on all recommendations and indicators of the guideline. The questionnaire was only validated on content and clarity by experts, but no test-retest of the questionnaire was performed.

Second, as a self-reporting questionnaire was used, there is a possibility of an over- or under-estimation of compliance with the guideline as socially desirable answers may have been given. Third, the ward managers of each ED were asked to distribute the questionnaires to a triage nurse. This might have led to selection bias, as nurses could be chosen who already showed an interest in triage. They may have completed the questionnaire differently compared with other nurses at the department who do not agree with the department's policy concerning triage. Despite the possible bias, we feel this study gives a balanced overview of what the level of adherence to the guideline is.

A fourth limitation is related to the response of EDs and type of hospital. Although the all-response rate was relatively high $(75 \%$ of all EDs in the Netherlands), a difference in response rates was found between university, teaching and non-teaching hospitals. The university and teaching hospitals had a response of higher than $80 \%$, whereas nearly $70 \%$ of the non-teaching hospitals responded. Although this could have biased the results from the non-teaching hospitals, we feel that the answers of the non-teaching hospitals represents were well represented, as 50 EDs participated. Furthermore, we found only one significant difference between university/ teaching and non-teaching hospitals (registration of reason for not achieving target time).

\section{Conclusions}

In conclusion, dissemination of the 2004 guideline Triage in emergency departments appears to be good. Important sources of dissemination are the profession (NVSHV) and the ward managers. However, improvement is still required concerning the actual implementation of the guideline Triage in emergency departments. Further research into recent developments related to triage should be part of the updating process and dissemination of the guideline.

\section{Relevance to clinical practice}

Adherence to guidelines is important to reduce variations in practice and to ensure that patients receive the appropriate treatment and to improve quality of care. The results shown in this study suggest that the existence of a guideline does not mean that it is automatically transferred into daily practice. It also shows the need of further awareness for the use of performance indicators related to triage. More research on barriers that hinder the use of triage and strategies to implement triage in EDs is wanted. These research findings should support the revision and implementation of guidelines in EDs.

\section{Acknowledgement}

This study was funded by an unrestricted educational grant from the Foundation Innovation Alliance (SIA - Stichting 
Innovatie Alliantie) with funding from the ministry of Conflict of interest

Education, Culture and Science (OCW).

None declared.

\section{Contributions}

Study design: MJ, JM; data collection and analysis: MJ, CK, JM, TA and manuscript preparation: MJ, TA, MA, CK, JM.

\section{References}

Baumann MR \& Strout TD (2007) Triage of geriatric patients in the emergency department: validity and survival with the Emergency Severity Index. Annals of Emergency Medicine 49, 234-240.

Bergeron S, Gouin S, Baily B, Amre DK \& Patel H (2004) Agreement among pediatric health care professionals with the pediatric canadian triage and acuity scale guidelines. Pediatric Emergency Care 20, 514-518.

Cabana MD, Rand CS, Powe NR, Wu AW, Wilson MH, Abboud PA \& Rubin HR (1999) Why don't physicians follow clinical practice guidelines? A framework for improvements. The Journal of the American Medical Association 282, $1458-1465$.

Cronin JG (2003) The introduction of the Manchester triage scale to an emergency department in the Republic of Ireland. Accident and Emergency Nursing 11, 121-125.

De Vos MLG, Van der Veer SN, Graafmans WC, De Keizer NF, Jager KJ, Westert GP \& Van der Voort PHJ (2010) Implementing quality indicators in intensive care units: exploring barriers to and facilitators of behavior change. Implementation Science 5, 52.

Doumit G, Gattellari M, Grimshaw J \& O'Brien MA (2007) Local opinion leaders: effects on professional practice and health care outcomes. Cochrane Database of Systematic Reviews, Issue 1, Art. No. CD000125. Doi:10.1002/ 14651858.CD000125.pub3.

Eitel DR, Travers DA, Rosenau AM, Gilboy N \& Wuerz RC (2003) The emergency severity index triage algorithm version 2 is reliable and valid. Academic Emergency Medicine 10, 1070-1080.

Elshove-Bolk J, Mencl F, Van Rijswijck BTF, Simons MP \& Van Vugt $\mathrm{AB}$ (2007) Validation of the Emergency
Severity Index (ESI) in self-referred patients in a European Emergency department. Emergency Medical journal 24, 170-174.

Estabrooks CA (1998) Will evidence-based nursing practice make practice perfect? Canadian Journal of Nursing Research 30, 15-36.

Forsner T, Åberg Wistedt A, Brommels M \& Forsell Y (2008) An approach to measure compliance to clinical guidelines in psychiatric care. BMC Psychiatry 8, 64 .

Forsner T, Hansson J, Brommels M, Åberg Wistedt A \& Forsell Y (2010) Implementing clinical guidelines in psychiatry: a qualitative study of perceived facilitators or barriers. BMC Psychiatry 10,8 .

Francke AL, Smit MC, Veer de AJE \& Mistiaen P (2008) Factors influencing the implementation of clinical guidelines for health care professionals: a systematic meta-review. BMC Medical Informatics and Decision Making 8, 38.

Gerdtz MF \& Bucknall TK (2000) Australian triage nurses' decision- making and scope of practice. Australian Journal of Advanced Nursing 18, 24-33.

Gerdtz MF \& Bucknall TK (2007) Influence of task properties and subjectivity on consistency of triage: a simulation study. Journal of Advanced Nursing 58, 180-190.

Gilboy N, Tanabe P, Travers DA, Rosenau AM \& Eitel DR (2005) Emergency Severity Index, Version 4: Implementation Handbook. AHRQ Publication No. 05-0046-2. Agency for Healthcare Research and Quality, Rockville, MD.

Göransson KE, Ehrenberg A \& Ehnfors M (2005) Triage in emergency departments: national survey. Journal of Clinical Nursing 14, 1067-1074.

Grol R (1997) Beliefs and evidence in changing clinical practice. British Medical Journal 315, 418-421.
Grol R \& Wensing M (2005) Effective implementation: a model. In Improving Patient Care: The Implementation of Change in Clinical Practice (Grol R, Wensing $M$ \& Eccles $M$ eds). Elsevier, London, pp. 41-57.

Jochems P (2006) IGZ is helder in haar standpunt over de uitvoering van Triage door SEH-verpleegkundigen! Available at: http://www.trauma-nursing.nl/stnn/ modules/smartsection/item.php?itemid= 40 (accessed 4 February 2009).

Kitson AL, Rycroft-Malone J, Harvey G, McCormack B, Seers K \& Titchen A (2008) Evaluating the successful implementation of evidence into practice using the PARiHS framework: theoretical and practical challenges. Implementation Science 3, 1.

Manos DBA, Petrie DA, Beveridge RC, Walter S \& Ducharme J (2002) Interobserver agreement using the Canadian Emergency Department Triage and Acuity Scale. Canadian Journal of Emergency Medicine 4, 16-22.

McCallum Pardey TG (2006) The clinical practice of Emergency Department Triage: application of the Australasian Triage Scale - an extended literature review Part 1: evolution of the ATS. Australasian Emergency Nursing Journal 9, 155-162.

Meijers JMM, Janssen MAP, Cummings GG, Wallin L, Estabrooks CA \& Halfens RYG (2006) Assessing the relationships between contextual factors and research utilization in nursing: systematic literature review. Journal of Advanced Nursing 55, 622-635.

Murray M, Bullard M \& Grafstein E (2004) Revisions of the Canadian emergency department triage and acuity scale implementation guidelines. Canadian Journal of Emergency Medicine 6, 421427.

Nederlands Triage Systeem: op weg naar eenduidige triage (2006) Available at: 
http://www.nederlandstriagesysteem.nl/ (accessed 4 February 2009).

Nederlandse Vereniging Spoedeisende Hulp Verpleegkundigen (2004) Richtlijn Triage op de spoedeisende hulp. Van Zuiden Communications BV, Alphen aan den Rijn.

Nelen WLDM, Hermens RPMG, Mourad SM, Haagen EC, Grol RPTM \& Kremer JAM (2007) Monitoring reproductive health in Europe: what are the best indicators of reproductive health? A need for evidence-based quality indicators of reproductive health care. Human Reproduction 22, 916-918.

Ploeg J, Davies B, Edwards N, Gifford W \& Miller PE (2007) Factors influencing best-practice guideline implementation: lessons learned from administrators, nursing staff and project leaders. Worldviews on Evidence-Based Nursing 4, 210-219.

Rogers EM (1995) Diffusion of Innovations, 4th edn. The Free Press, New York.

Roukema J, Steyerberg EW, Van Meurs A, Ruige M, Van der Lei J \& Moll HA (2006) Validity of the Manchester Triage System in pediatric emergency care.
Emergency Medicine Journal 23, 906910.

Speake D, Teece S \& Mackway-Jones K (2003) Detecting high-risk patients with chest pain. Emergency Nurse 11, 19-21.

Storm-Versloot MN, Ubbink DT, Chin a Choi V \& Luitse JS (2009) Observer agreement of the Manchester Triage System and the Emergency Severity Index: a simulation study. Emergency Medicine Journal 26, 556-560.

Travers DA, Waller AE, Bowling JM, Flowers D \& Tintinalli J (2002) Fivelevel triage system more effective than three-level in tertiary emergency department. Journal of Emergency Nursing 28, 395-400.

Van der Wulp I, Van Baar ME \& Schrijvers AJP (2008) Reliability and validity of the Manchester Triage System in a general emergency department patient population in the Netherlands: results of a simulation study. Emergency Medicine Journal 25, 431-434.

Van Gerven R, Delooz H \& Sermeus W (2001) Systematic triage in the emergency department using the Australian National Triage Scale: a pilot project. European Journal of Emergency Medicine 8, 3-7.
Van Veen M \& Moll HA (2009) Reliability and validity of triage systems in paediatric emergency care. Scandinavian Journal of Trauma, Resuscitation and Emergency Medicine 17, 38.

Van Veen M, Steyerberg EW, Ruige M, Van Meurs AHJ, Roukema J, Van der Lei J \& Moll HA (2008) Manchester triage system in paediatric emergency care: prospective observational study. British Medical Journal 337, a1501. Doi: 10.1136/bmj.a1501.

Wollersheim H, Burgers J \& Grol R (2005) Clinical guidelines to improve patient care. The Netherlands Journal of Medicine 63, 188-192.

Woolf SH, Grol R, Hutchinson A, Eccles M \& Grimshaw J (1999) Clinical guidelines: potential benefits, limitations and harms of clinical guidelines. British Medical Journal 318, 527-530.

Worster A, Gilboy N, Fernandes CM, Eitel D, Eva K, Geisler R \& Tanabe P (2004) Assessment of inter-observer reliability of two five-level triage and acuity scales: a randomized controlled trial. Canadian Journal of Emergency medicine 6, 240-245.

\section{Appendix}

\section{Questionnaire}

General questions
1. Type of hospital*
3. Knowledge of existence of the guideline 'Triage at the emergency departments"
4. Use of (type) triage system*
(in case of no use of any kind of triage system, the questionnaire stopped here)
5. Reason for the use of the specific type of a triage system
6. Patients are triaged after arrival at the ED
7. Triage take place within 5 minutes after arrival at the ED
8. Triage leads within $3-5$ minutes to an urgency rating
9. Pain assessment is part of triage; if yes, which scale is used?
10. Patients are informed on urgency code, waiting times and retriage
11. During waiting times, complaint related interventions are put in motions.
Which interventions? Is this according to a specific protocol?
12. Who is responsible for patients in the waiting room?
13. There is a working agreement for triage. What agreements does this contain?
How is the agreement drawn up?
14. There are information brochure at the ED. Do all patients receive this brochure?
15. Nurses are competent to determine the urgency rating, informing patients on urgency rating and waiting time
16. The percentage of nurses who have followed (1) an education in acute care; (2) the Trauma Nursing
Core Course (TNCC); (3) the Emergency Nursing Paediatric Course (ENPC); (4) training in triage; and (5) more
than one year work experience at the ED
17. All steps of triage registered by the triage nurse (complaint; flow chart; discriminator; pain score; urgency code)




\section{Appendix (Continued)}

\begin{tabular}{|c|c|}
\hline $\begin{array}{l}\text { Implementation of } \\
\text { triage }\end{array}$ & $\begin{array}{l}\text { 18. Top-down implementation } \\
\text { 19. Multidisciplinary implementation } \\
\text { 20. Communication in terms of policy and instructions; consultation; information services; measurement and } \\
\text { evaluation moments; feedback on (temporary) results } \\
\text { 21. Involvement of a change agent } \\
\text { 22. A triage room is available; how is this facilitated (second exit; alarm button; presence of camera, disinfectants, } \\
\text { examination gloves, hand basin, other facilitations) } \\
\text { 23. Training in triage: (1) multidisciplinary, (2) time between training and implementation, ( } 3 \text { ) all new employees } \\
\text { receive the training, if yes how, (4) trail to get acquaintance in triage (how long, evaluation after the trail, } \\
\text { adjustments after trail) } \\
\text { 24. Reflection moments related to the triage process in multidisciplinary team } \\
\text { 25. Reflection moments related to triage process in monodisciplinary team } \\
\text { 26. A triage group is formulated } \\
\text { 27. Information Communication Technology system (ICT) is present } \\
\text { 28. Budget reserved for costs related to the implementation of triage (ICT, formation, training, information } \\
\text { brochure, renovation costs for waiting room, other) }\end{array}$ \\
\hline $\begin{array}{l}\text { Quality indicators } \\
\text { (only filled in by } \\
\text { ward managers) }\end{array}$ & $\begin{array}{l}\text { 29. Triage is imbedded in quality system } \\
\text { 30. Use of quality indicators of the guideline } \\
\text { 31. Registration of origin patient } \\
\text { 32. Registration of urgency codes } \\
\text { 33. Registration of moment of arrival at the ED until first contact nurse } \\
\text { 34. Registration of triage time (moment contact patients with nurse) } \\
\text { 35. Registration target time (first contact patients with doctors); conform the guideline } \\
\text { 36. Registration reason not meeting the target time } \\
\text { 37. Registration time patients leaving the ED } \\
\text { 38. Registration outflow reasons } \\
\text { 39. Registration reason retriaged patients } \\
\text { 40. Evaluation of patient experience (information on waiting times and urgency codes, pain, privacy and treatment) } \\
\text { 41. Evaluation of experiences personnel (aggression, triage system, ICT system, triage room) } \\
\text { 42. Registration of aggression per month/year at the ED (before/after triage) } \\
\text { 43. Decrease in waiting times after implementation of triage } \\
\text { 44. Decrease in completion time after implementation of triage }\end{array}$ \\
\hline
\end{tabular}

If questions were filled in with 'no', reasons why not were asked.

*Filled in by all participants.

The Journal of Clinical Nursing (JCN) is an international, peer reviewed journal that aims to promote a high standard of clinically related scholarship which supports the practice and discipline of nursing.

For further information and full author guidelines, please visit JCN on the Wiley Online Library website: http:// wileyonlinelibrary.com/journal/jocn

\section{Reasons to submit your paper to JCN:}

High-impact forum: one of the world's most cited nursing journals and with an impact factor of 1.228 - ranked 23 of 85 within Thomson Reuters Journal Citation Report (Social Science - Nursing) in 2009.

One of the most read nursing journals in the world: over 1 million articles downloaded online per year and accessible in over 7000 libraries worldwide (including over 4000 in developing countries with free or low cost access).

Fast and easy online submission: online submission at http://mc.manuscriptcentral.com/jcnur.

Early View: rapid online publication (with doi for referencing) for accepted articles in final form, and fully citable.

Positive publishing experience: rapid double-blind peer review with constructive feedback.

Online Open: the option to make your article freely and openly accessible to non-subscribers upon publication in Wiley Online Library, as well as the option to deposit the article in your preferred archive. 